\title{
Compact Multiband Slot Antenna for WLAN/WiMAX Operations
}

\author{
Jianhui Bao, Qiulin Huang, Xinhuai Wang, and Xiaowei Shi \\ Science and Technology on Antenna and Microwave Laboratory, Xidian University, Xian 710071, China \\ Correspondence should be addressed to Qiulin Huang; qiulhuang@mail.xidian.edu.cn
}

Received 29 December 2013; Accepted 29 March 2014; Published 15 April 2014

Academic Editor: Z. N. Chen

Copyright (C) 2014 Jianhui Bao et al. This is an open access article distributed under the Creative Commons Attribution License, which permits unrestricted use, distribution, and reproduction in any medium, provided the original work is properly cited.

\begin{abstract}
A novel compact triple-band slot antenna is proposed for WLAN/WiMAX applications. With the use of three L-shaped slots and an open-ended slot on the ground plane, three resonant modes centered at $2.4 / 3.5 / 5.8 \mathrm{GHz}$ are excited. These modes cover the standards of $3.5 \mathrm{GHz}$ WiMAX and $2.4 / 5.8 \mathrm{GHz}$ WLAN, three useful frequency bands for present wireless communication systems. The proposed antenna fed by L-shaped microstrip line has a small overall dimension of $16 \times 30 \mathrm{~mm}^{2}$. The numerical and experimental results show that acceptable radiation characteristic is obtained over the operating bands.
\end{abstract}

\section{Introduction}

With the rapid development of the modern wireless communication technology, the wireless local area network (WLAN) which operates in the frequency band of 2.42.484 GHz/5.15-5.35 GHz/5.725-5.825 GHz and worldwide interoperability for microwave access (WiMAX) system covering $3.4-3.69 \mathrm{GHz}$ have been widely used in mobile devices. Meanwhile, small communication terminals lead to a great demand in integrating various services to collaborate with each other. Accordingly, antenna design has turned to focus on multiband and small simple structures. Some monopole antennas for multiband applications, such as dual U-shape [1], T-shaped [2], double-T shape [3], fork-shaped $[4,5]$, trident-shaped [6], and meandering microstrip lineloaded [7] applications, have been reported. Slot antennas are another popular design for multiband applications. However, the printed slot antenna used in multiband operation design is relatively less in the open literature. In [8-10], bow-tieslot, T-slot, and ring-slot antennas provide dual or triple resonant modes for different wireless communication systems. Although these antenna designs mentioned above can achieve dual or multiple band property, they are somewhat large in size, which are not perfectly practical for small communication terminals.
In this paper, a novel compact microstrip-fed slot antenna designed with triple-band operations is proposed for WLAN and WiMAX applications. In the proposed design, the antenna structure consists of two L-shaped slots and an openended slot on the ground plane that is excited by an L-shaped microstrip feed line. Meanwhile, another etching small Lshaped coupling slot makes a positive effect to enhance the bandwidth of $3.5 \mathrm{GHz}$ and improve the impedance match condition of $5.8 \mathrm{GHz}$. These design skills are introduced to approach excitation of triple resonant modes accompanied with good impedance bandwidths at 2.4/3.5/5.8 GHz. Furthermore, acceptable radiation characteristics can be obtained over the operating bands.

\section{Antenna Design}

Figure 1 depicts the configuration of the proposed triple-band slot antenna. The antenna is fabricated on a thin FR4 substrate of thickness $1.0 \mathrm{~mm}$, with relative dielectric constant of 4.4 .

In the antenna design, the middle L-shaped slot (named Slotl) with horizontal part $a_{1}$ and the vertical part $b_{1}$ controls the resonant mode at $2.4 \mathrm{GHz}$, of which the notch is used to improve the impedance match of the proposed antenna. The L-shaped slot has smaller dimension compared to the common open-ended slot for the same resonant frequency, which 


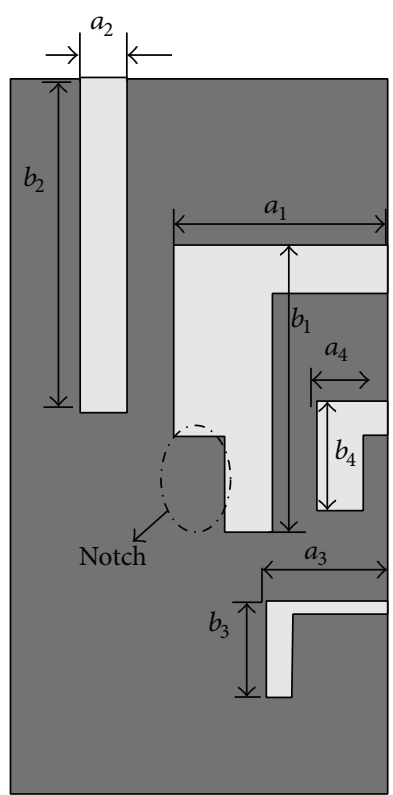

Top view

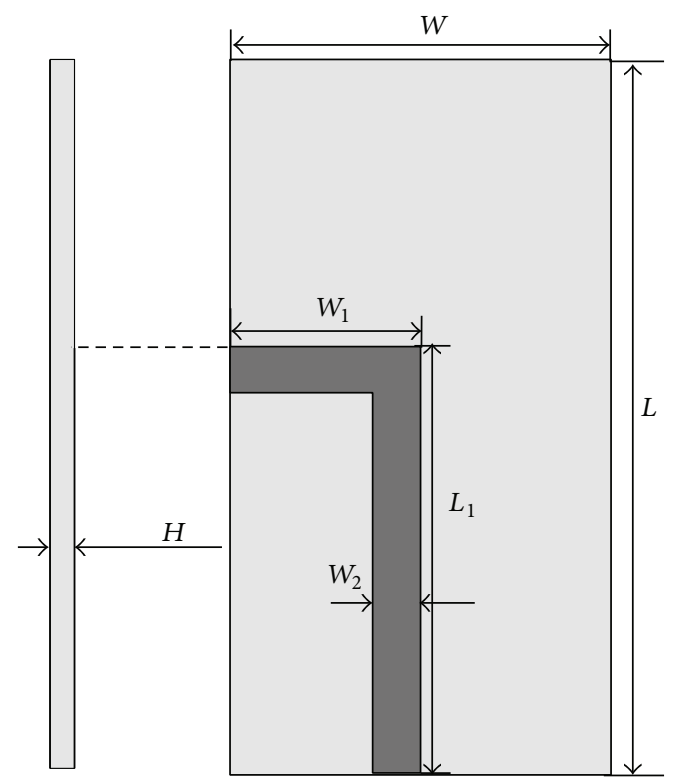

Side view

Bottom view

Figure 1: Geometry of the proposed triple-frequency slot antenna.

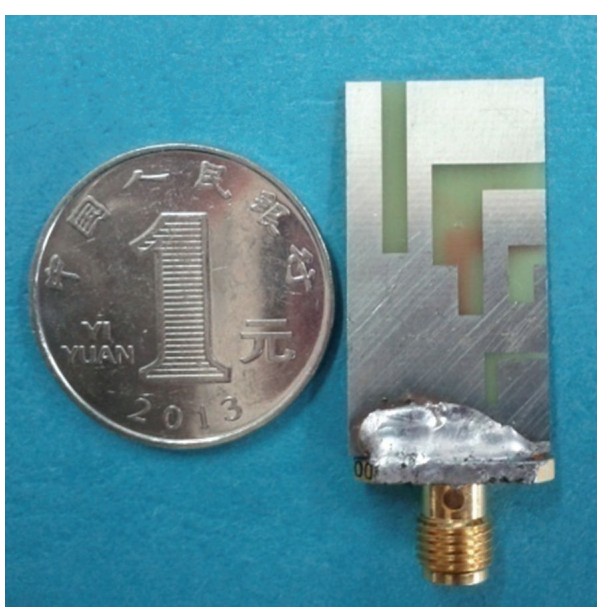

(a) Top view

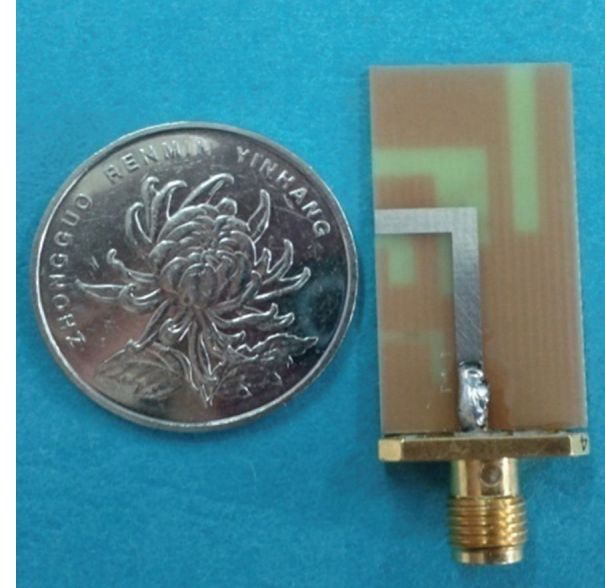

(b) Bottom view

FIgURE 2: Photograph of the fabricated prototype.

TABLE 1: The optimal antenna parameters (unit: $\mathrm{mm}$ ).

\begin{tabular}{cccccccccccccc}
\hline$W$ & $W_{1}$ & $W_{2}$ & $L$ & $L_{1}$ & $H$ & $a_{1}$ & $a_{2}$ & $a_{3}$ & $a_{4}$ & $b_{1}$ & $b_{2}$ & $b_{3}$ & $b_{4}$ \\
\hline 16 & 8 & 2 & 30 & 16 & 1 & 9 & 2 & 5 & 3 & 12 & 14 & 4 & 4.5 \\
\hline
\end{tabular}




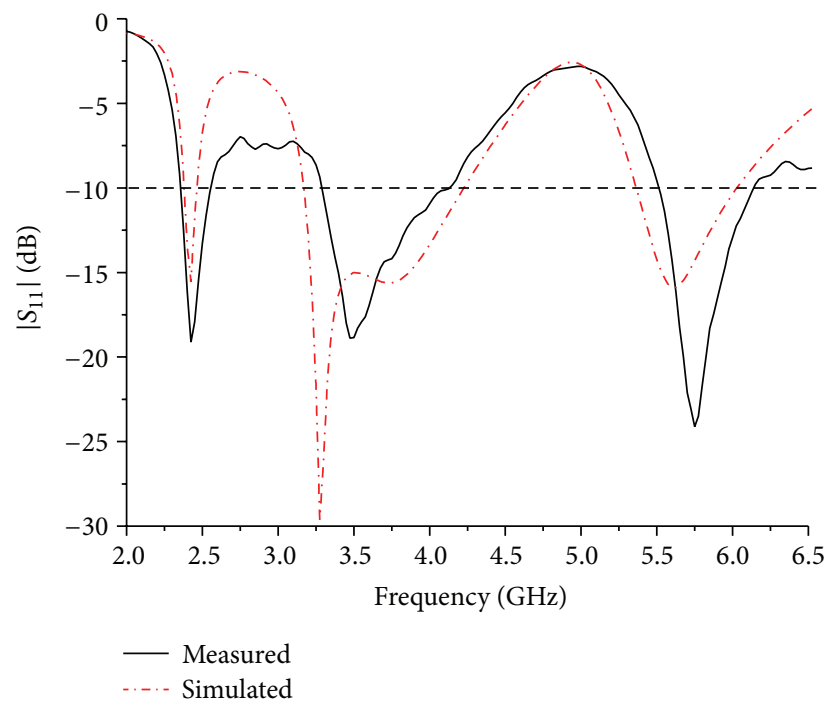

FIGURE 3: Simulated and measured $\left|S_{11}\right|$ of proposed antenna.

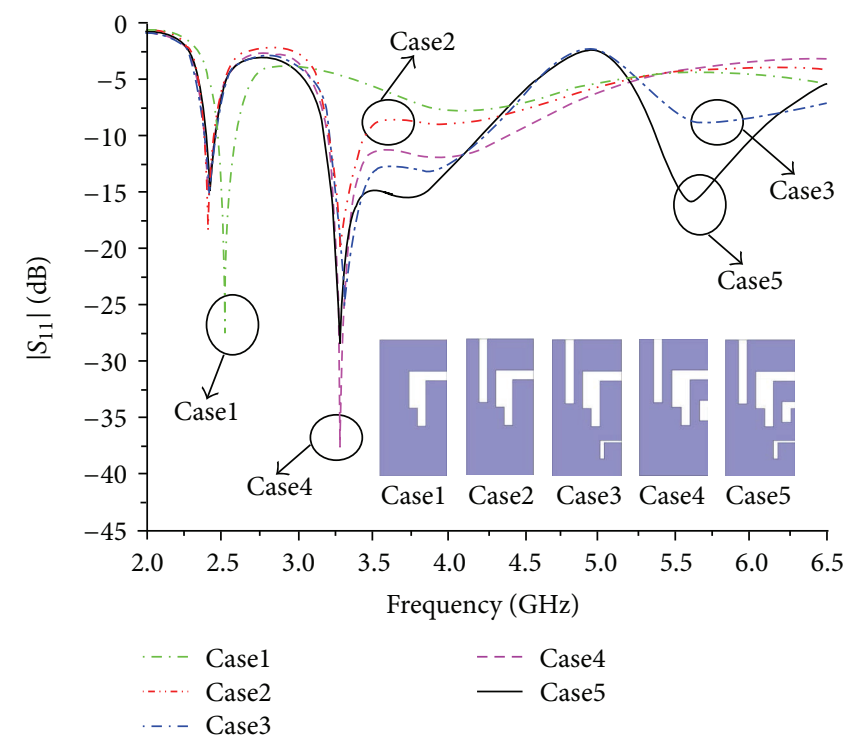

FIGURE 4: Simulated $\left|S_{11}\right|$ of antennas with various slots involved.

is more conducive to the miniaturization of antenna design. The resonant frequency $f_{1}$ can be roughly approximated by

$$
\begin{aligned}
f_{1} & =\frac{c}{\sqrt{\varepsilon_{\mathrm{eff}}} \cdot \lambda_{g}} \approx \frac{c}{\sqrt{\varepsilon_{\mathrm{eff}}} \cdot 4 \cdot l_{\text {slot } 1}}, \\
\varepsilon_{\mathrm{eff}} & \approx \frac{\varepsilon_{r}+1}{2}, \\
l_{\text {slot } 1} & =a_{1}+b_{1} .
\end{aligned}
$$

In order to be compact in size as operating, an openended slot is embedded near Slotl to have minimum antenna dimension for compact operation. The open-ended slot (named Slot2) occupying $a_{2} \times b_{2}$ acts as the excitation of the second resonant mode centered at $3.5 \mathrm{GHz}$. The resonant frequency $f_{2}$ can be roughly approximated by

$$
\begin{aligned}
f_{2} & =\frac{c}{\sqrt{\varepsilon_{\mathrm{eff}}} \cdot \lambda_{g}} \approx \frac{c}{\sqrt{\varepsilon_{\mathrm{eff}}} \cdot 4 \cdot l_{\text {slot2 }}}, \\
l_{\text {slot2 }} & =b_{2} .
\end{aligned}
$$

To introduce the upper resonant mode at $5.8 \mathrm{GHz}$ WLAN, another L-shaped slot (named Slot3), comprised of the horizontal $\operatorname{arm} a_{3}$ and the vertical arm $b_{3}$, is etched on the right side of the ground, which also has good effect on $3.5 \mathrm{GHz}$ mode bandwidth enhancement. The resonant 


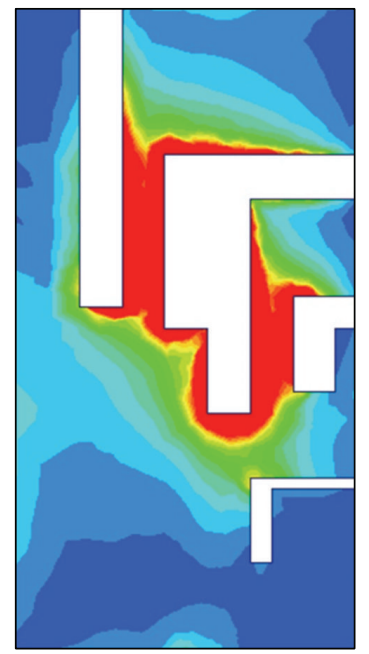

(a) $2.44 \mathrm{GHz}$

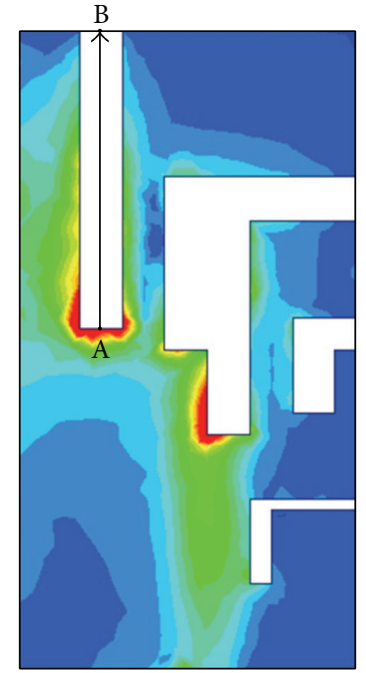

(b) $3.5 \mathrm{GHz}$
$J_{\text {surf }}$ (A_per_m)

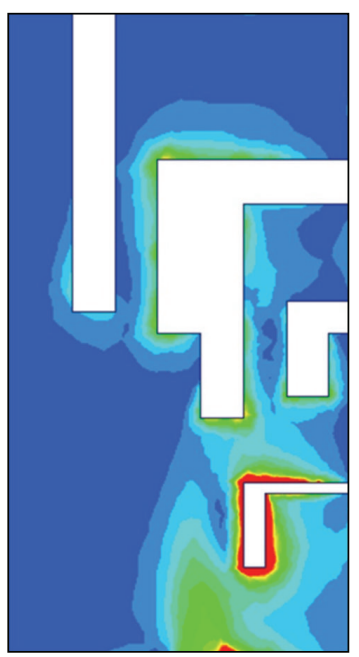

(c) $5.8 \mathrm{GHz}$
$1.0000 e+002$

$9.2887 e+001$

$8.5774 e+001$

$7.8661 e+001$

$7.1549 e+001$

$6.4436 e+001$

$5.7323 e+001$

$5.0210 e+001$

$4.3097 e+001$

$3.5984 e+001$

$2.8872 e+001$

$2.1759 e+001$

$1.4646 e+001$

$7.5330 e+000$

$4.2017 e-001$

FIGURE 5: Surface current distribution at different frequencies.

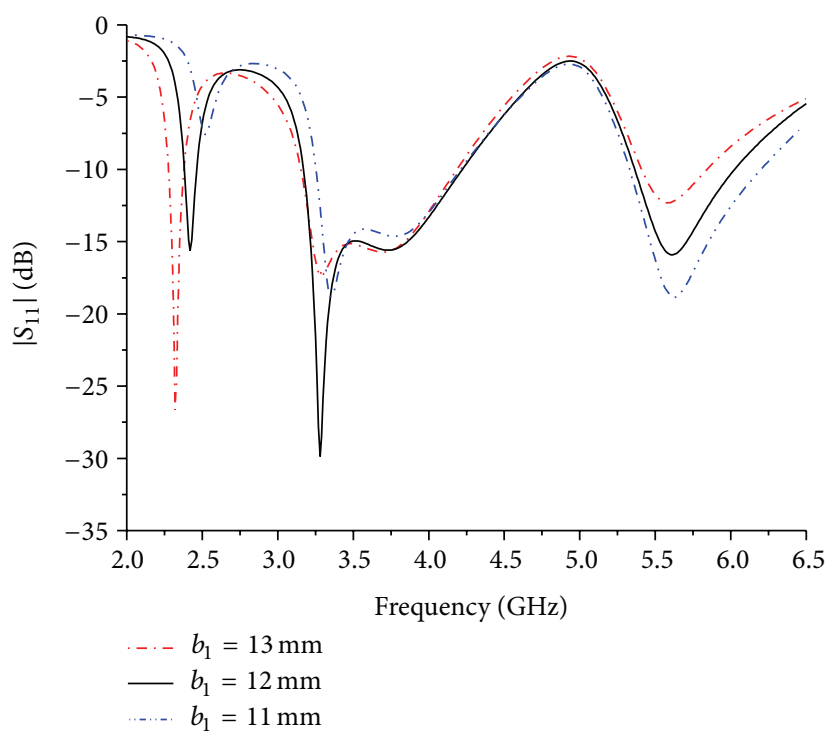

FIGURE 6: $\left|S_{11}\right|$ variations for different values of slot's length $b_{1}$.

frequency $f_{3}$ has the same exciting principle as the resonant frequency $f_{1}$; that is,

$$
\begin{aligned}
f_{3} & =\frac{c}{\sqrt{\varepsilon_{\mathrm{eff}}} \cdot \lambda_{g}} \approx \frac{c}{\sqrt{\varepsilon_{\mathrm{eff}}} \cdot 4 \cdot l_{\text {slot3 }}}, \\
l_{\text {slot3 }} & =a_{3}+b_{3} .
\end{aligned}
$$

Finally, owning to another small coupling L-shaped slot (named Slot4) is introduced aiming to improve the impedance match of resonant mode centered at $5.8 \mathrm{GHz}$ and further broaden the bandwidth of $3.5 \mathrm{GHz}$. On the other hand, the slots are electromagnetically fed by a $50 \Omega \mathrm{L}$-shaped microstrip feed line on the other side of board.
An electromagnetic software package, Ansoft HFSS based on the finite element method, is used for required numerical analysis to examine the performance of the proposed antenna design. By iterative trials, the final optimal dimension values are obtained and listed in Table 1.

\section{Results and Discussions}

A prototype of the proposed antenna was experimentally fabricated and measured to support the EM simulation. Figure 2 presents the photograph of the fabricated antenna, and a $50 \Omega$-SMA connector is used to feed the antenna. 


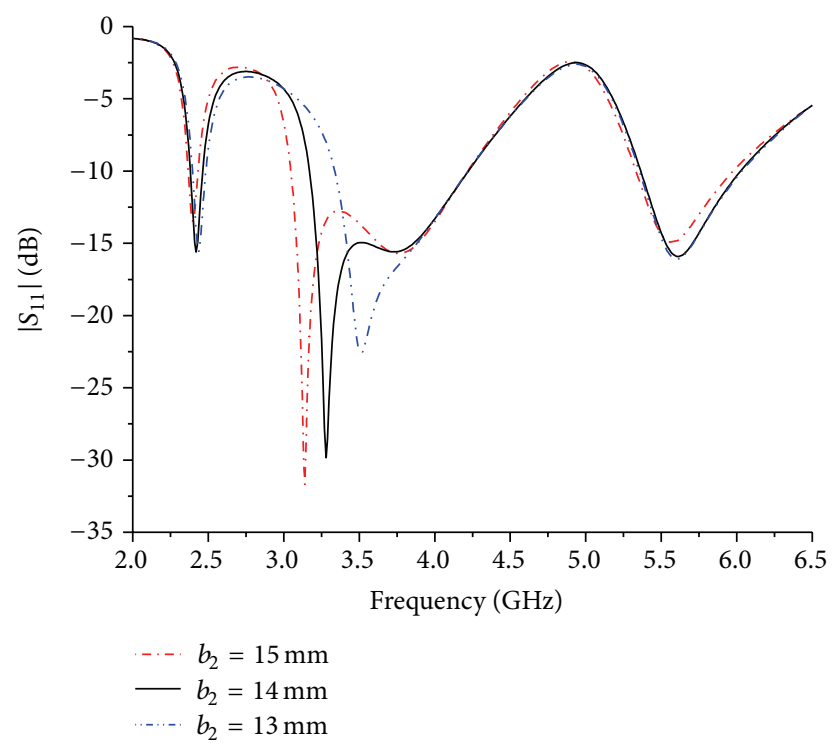

FIGURE 7: $\left|S_{11}\right|$ variations for different values of slot's length $b_{2}$.

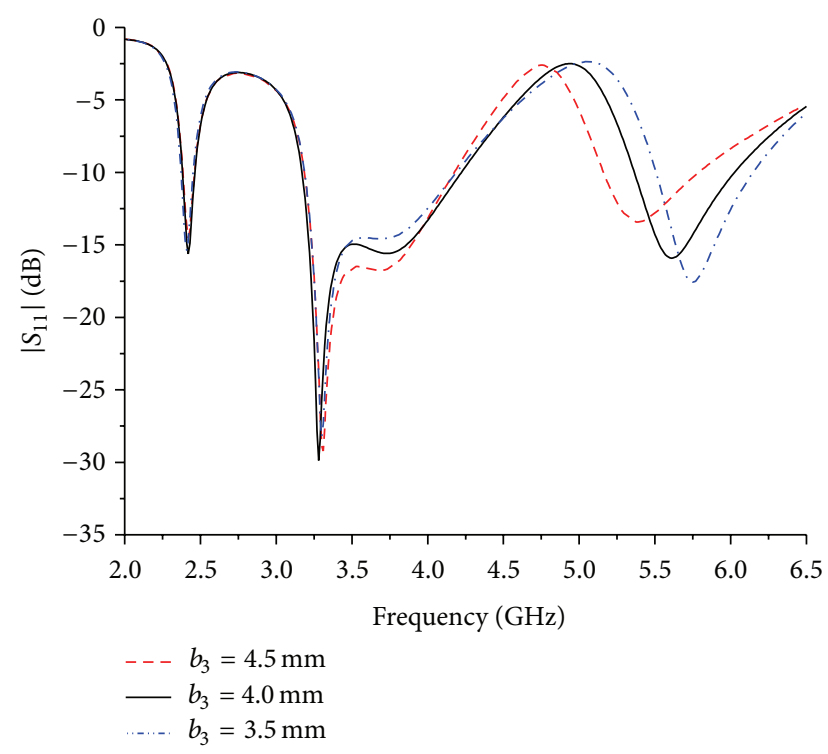

FIGURE 8: $\left|S_{11}\right|$ variations for different values of slot's length $b_{3}$.

The simulated and measured reflection coefficients $\left(\left|S_{11}\right|\right)$ of the proposed triband slot antenna are illustrated in Figure 3. Reasonable agreements between the simulation and measurement results are attained. Some slight discrepancies between them may be attributed to measurement errors, inaccuracies in the fabrication process, and the impact of the SMA connector. As observed and measured, the proposed antenna achieves three resonant modes over the frequency ranges of $2.35-2.55 \mathrm{GHz}, 3.28-4.15 \mathrm{GHz}$, and $5.5-6.1 \mathrm{GHz}$ for $\left|S_{11}\right|<-10 \mathrm{~dB}$, simultaneously covering the $2.4 / 5.8 \mathrm{GHz}-$ WLAN and $3.5 \mathrm{GHz}$-WiMAX operation bands.

To further examine the effect of each slot on the proposed antenna's triple-resonance situations, the frequency response of $\left|S_{11}\right|$ for proposed antenna with different slots embedment is analyzed and presented in Figure 4. For the case of the antenna only with Slotl (Casel), the fundamental mode around $2.5 \mathrm{GHz}$ is excited. As for the antenna with Slot1 and Slot2 in Case2, the resonant frequency around $2.5 \mathrm{GHz}$ in Casel is shifted to lower band centered at $2.4 \mathrm{GHz}$ and the second resonant situation around $3.5 \mathrm{GHz}$ is emerged, while the bandwidth cannot cover the bandwidth of WiMAX system. When Slot3 is inserted into the antenna of Case2, the bands of $3.5 \mathrm{GHz}$ are broadened to satisfy the bandwidth requirements of WiMAX system and the upper resonant mode at $5.8 \mathrm{GHz}$-WLAN is excited though the matching condition is worse than the situation of the proposed antenna. Slot3 is not only as the exciting of the resonant mode at $5.8 \mathrm{GHz}$ but also as a coupling slot which is equivalent to provide additional coupling current path to broaden the impedance bandwidth of $3.5 \mathrm{GHz}$. As for the antenna in Case4, an interesting phenomenon that the impedance bandwidth of resonant mode centered at $3.5 \mathrm{GHz}$ is broadened to $3.2 \mathrm{GHz}-4.38 \mathrm{GHz}$ emerged, which shows that Slot 4 has the same effect as Slot 3 on broadening the bandwidth of resonance frequency $3.5 \mathrm{GHz}$. In the proposed antenna case, triple resonant frequencies are achieved; meanwhile, better impedance match situation at $3.5 \mathrm{GHz}-\mathrm{WiMAX}$ and $5.8 \mathrm{GHz}-$ WLAN operation bands is obtained than the antenna in Case3.

For better understanding the excitation behavior of the proposed antenna, the surface current distributions at $2.44 \mathrm{GHz}, 3.5 \mathrm{GHz}$, and $5.8 \mathrm{GHz}$, obtained from the HFSS simulation, are studied and displayed in Figure 5. For the lower band at $2.44 \mathrm{GHz}$, the large surface current density could be observed along Slotl. Figure 5(b) shows the simulated current distribution of Slot2 at the operating frequency of $3.5 \mathrm{GHz}$. It is observed that the current distribution is mainly along the side of Slot 2, maximum one is emerged at point $\mathrm{A}$ and the minimum one at point $\mathrm{B}$. For the higher band at $5.8 \mathrm{GHz}$, the surface current distribution in Figure 5(c) is similar to that of Slotl at $2.44 \mathrm{GHz}$ band. Thus, both from $\left|S_{11}\right|$ responses and surface current distributions, the function of the related geometrical mechanism on the impedance matching condition of the three resonant modes is clearly presented.

According to the observed phenomena in current distribution and frequency response of $\left|S_{11}\right|$ in different cases, some vital parameters are analyzed on resonant frequency bands. Figure 6 presents the tuning effect of length $b_{1}$ on the $\left|S_{11}\right|$ curves of the resonant mode at $2.44 \mathrm{GHz}$. As the length $b_{1}$ is increased, the center resonant frequency of $2.44 \mathrm{GHz}$ band is shifted towards lower frequency, and as the length $b_{1}$ is decreased, the center resonant frequency of $2.44 \mathrm{GHz}$ band is shifted towards higher frequency. The reason for this is that the longer $b_{1}$ is, the longer wavelength at relevant resonant frequency is, and vice versa, which conforms to theoretical formula (1). Similarly, the changing of $b_{2}$ and $b_{3}$ has the same impact on the resonant point of $3.5 \mathrm{GHz}$ band and $5.8 \mathrm{GHz}$ band, respectively, as shown in Figures 7 and 8.

The measured and simulated radiation patterns in main cut planes at $2.44 \mathrm{GHz}, 3.5 \mathrm{GHz}$, and $5.8 \mathrm{GHz}$ are shown in Figure 9. From an overall view, the antenna behaves in 

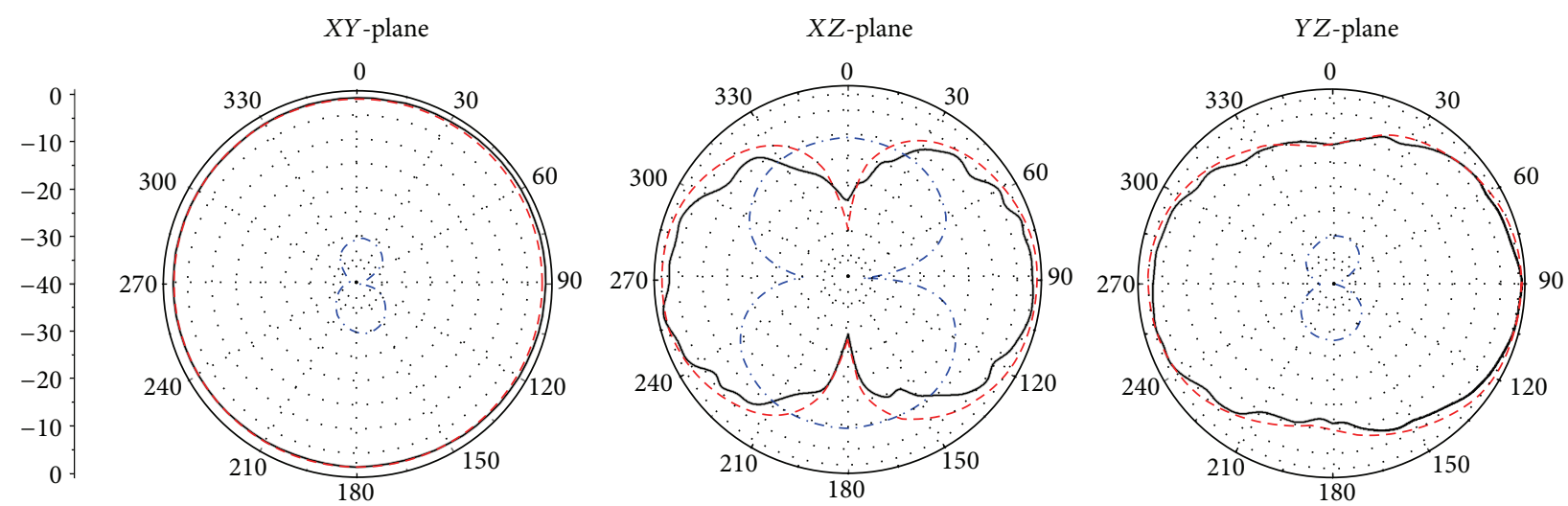

(a) $f=2.44 \mathrm{GHz}$
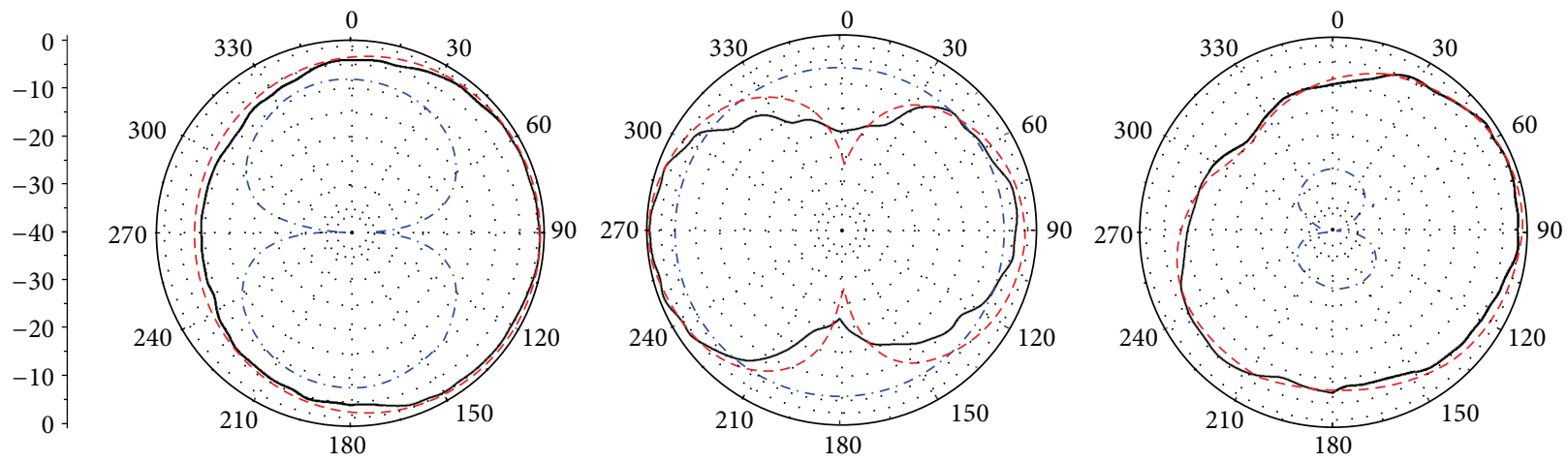

(b) $f=3.5 \mathrm{GHz}$
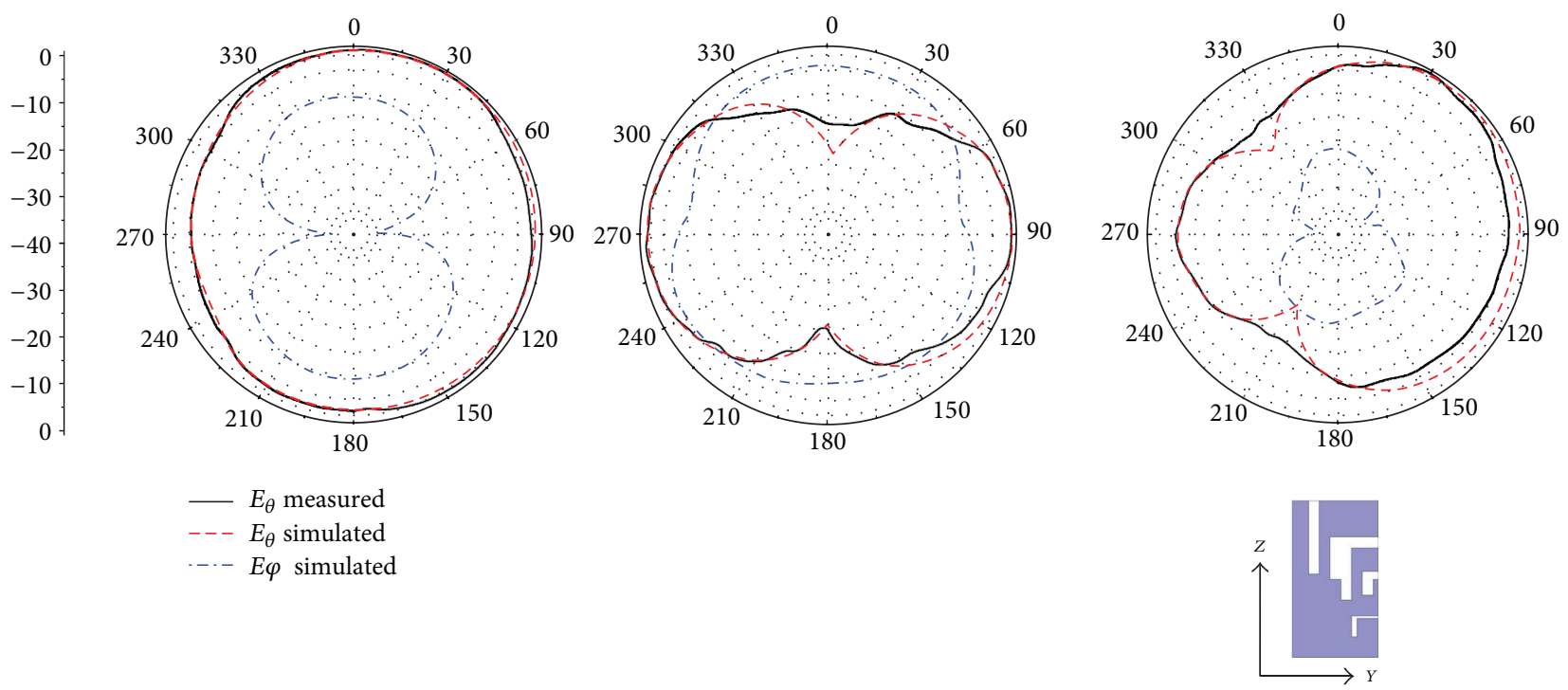

(c) $f=5.8 \mathrm{GHz}$

FIGURE 9: Radiation patterns in main cut planes.

nearly omnidirectional performance at $X Y$-plane. Reasonable agreements between the simulation and measurement results for $E_{\theta}$ are attained. The measured peak gain of the proposed antenna is depicted in Figure 10. As observed, acceptable radiation performance is achieved at triple operation bands.

\section{Conclusion}

A novel compact microstrip-fed slot antenna with tripleband operation is presented and investigated. With the skills of etching three L-shaped slot and an open-ended slot, the proposed slot antenna shows the compactness in the size of 


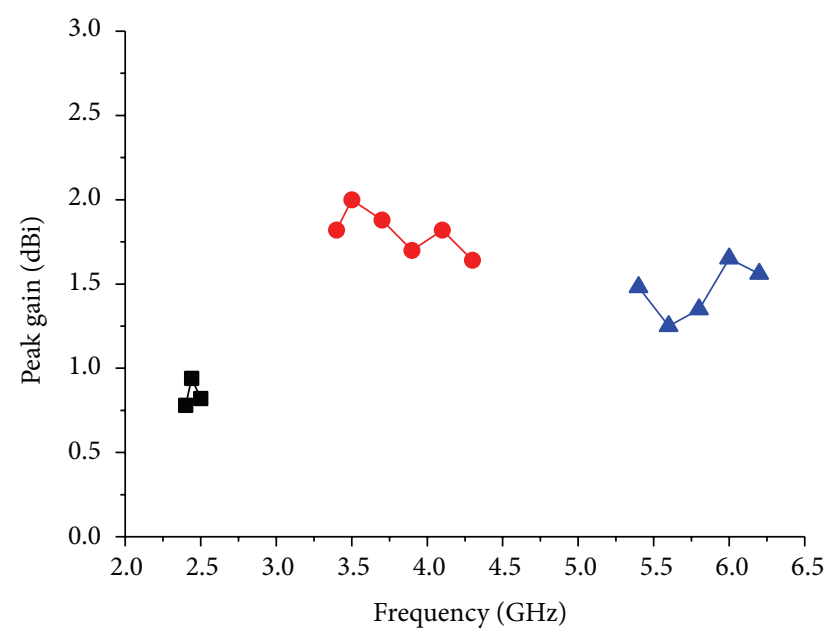

FIGURE 10: Measured peak gains of proposed antenna.

$16 \times 30 \mathrm{~mm}^{2}$ and exhibits triple-frequency resonant performance at 2.4/3.5/5.8 GHz. Furthermore, acceptable radiation characteristics are obtained across the operation bands. Consequently, the proposed slot antenna design could be promising and suitable for $3.5 \mathrm{GHz}$ WiMAX and $2.4 / 5.8 \mathrm{GHz}$ WLAN applications.

\section{Conflict of Interests}

The authors declare that there is no conflict of interests regarding the publication of this paper.

\section{References}

[1] J.-H. Lu and W.-C. Chou, "Planar dual U-shaped monopole antenna with multiband operation for IEEE 802.16e," IEEE Antennas and Wireless Propagation Letters, vol. 9, pp. 1006-1009, 2010.

[2] J. J. Wang and X. D. He, "Analysis and design of a novel compact multiband printed monopole antenna," International Journal of Antennas and Propagation, vol. 2013, Article ID 694819, 8 pages, 2013.

[3] Y.-L. Kuo and K.-L. Wong, "Printed double-T monopole antenna for 2.4/5.2 Ghz dual-band WLAN operations," IEEE Transactions on Antennas and Propagation, vol. 51, no. 9, pp. 2187-2192, 2003.

[4] H.-C. Go and Y.-W. Jang, "Multi-band modified fork-shaped microstrip monopole antenna with ground plane including dual-triangle portion," Electronics Letters, vol. 40, no. 10, pp. 575-577, 2004.

[5] P. Xu, Z.-H. Yan, and C. Wang, "Multi-band modified forkshaped monopole antenna with dual L-shaped parasitic plane," Electronics Letters, vol. 47, no. 6, pp. 364-365, 2011.

[6] C. Wang, Z.-H. Yan, P. Xu, J.-B. Jiang, and B. Li, “Tridentshaped dual-band CPW-fed monopole antenna for PCS/WLAN applications," Electronics Letters, vol. 47, no. 4, pp. 231-232, 2011.

[7] Y. Yao, X. Wang, and J. Yu, "Multiband planar monopole antenna for LTE MIMO systems," International Journal of Antennas and Propagation, vol. 2012, Article ID 890705, 6 pages, 2012.
[8] C.-Y. Huang, C.-C. Lin, and W.-F. Chen, "Multiple band-stop bow-tie slot antennas for multiband wireless systems," IET Microwaves, Antennas and Propagation, vol. 2, no. 6, pp. 588593, 2008.

[9] W. Ren, Z. Shi, H. Liu, and K. Chen, "Novel compact 2.4/5-GHz dual-band T-slot antenna for wlan operations," Microwave and Optical Technology Letters, vol. 49, no. 6, pp. 1236-1238, 2007.

[10] J.-S. Chen, "Dual-frequency annular-ring slot antennas fed by CPW feed and microstrip line feed," IEEE Transactions on Antennas and Propagation, vol. 53, no. 1, pp. 569-573, 2005. 

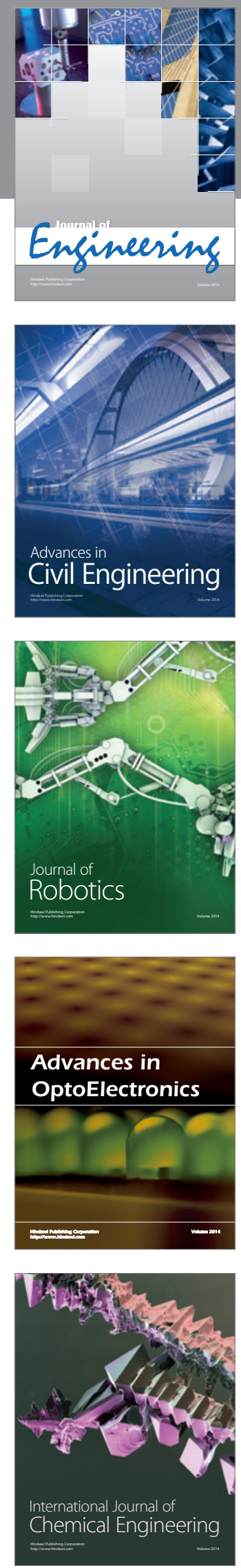

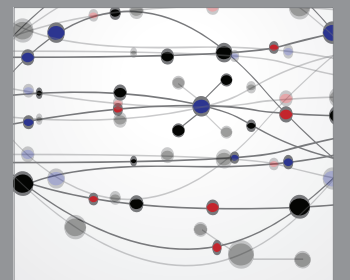

The Scientific World Journal
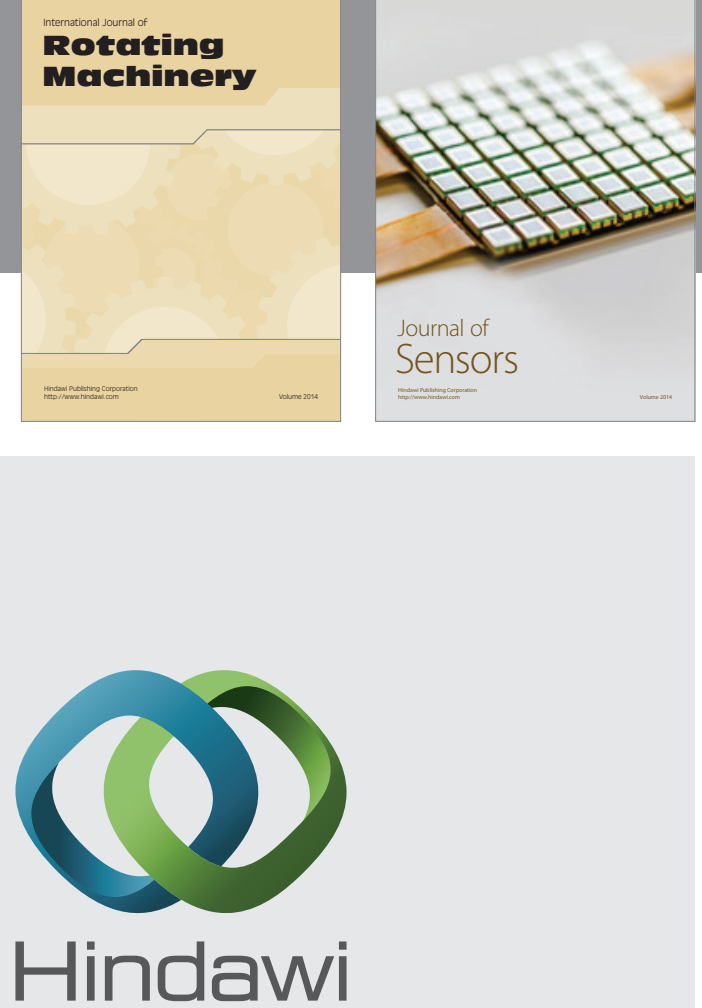

Submit your manuscripts at http://www.hindawi.com
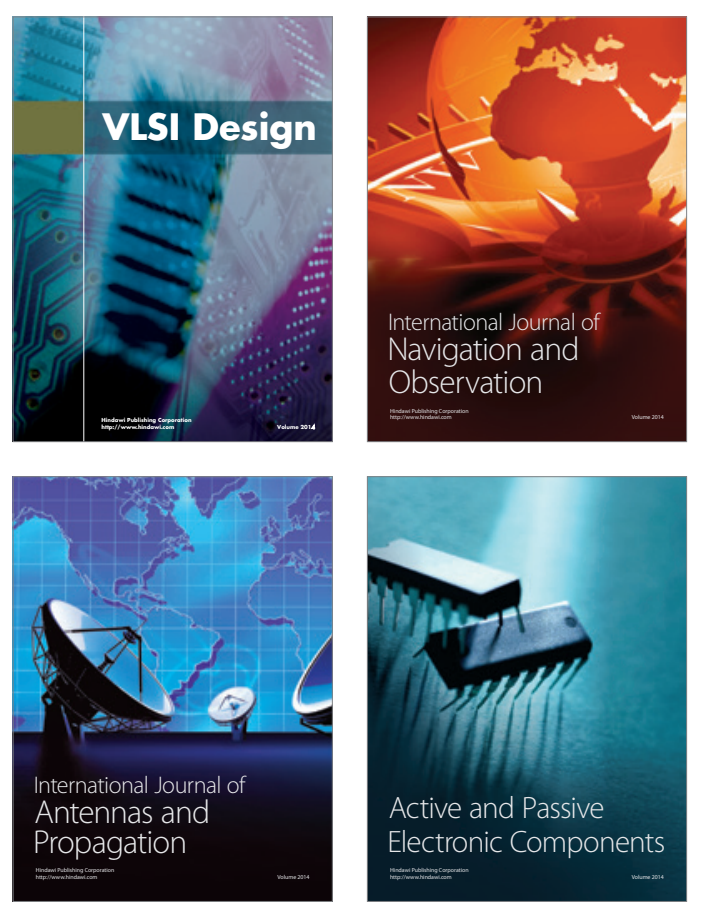
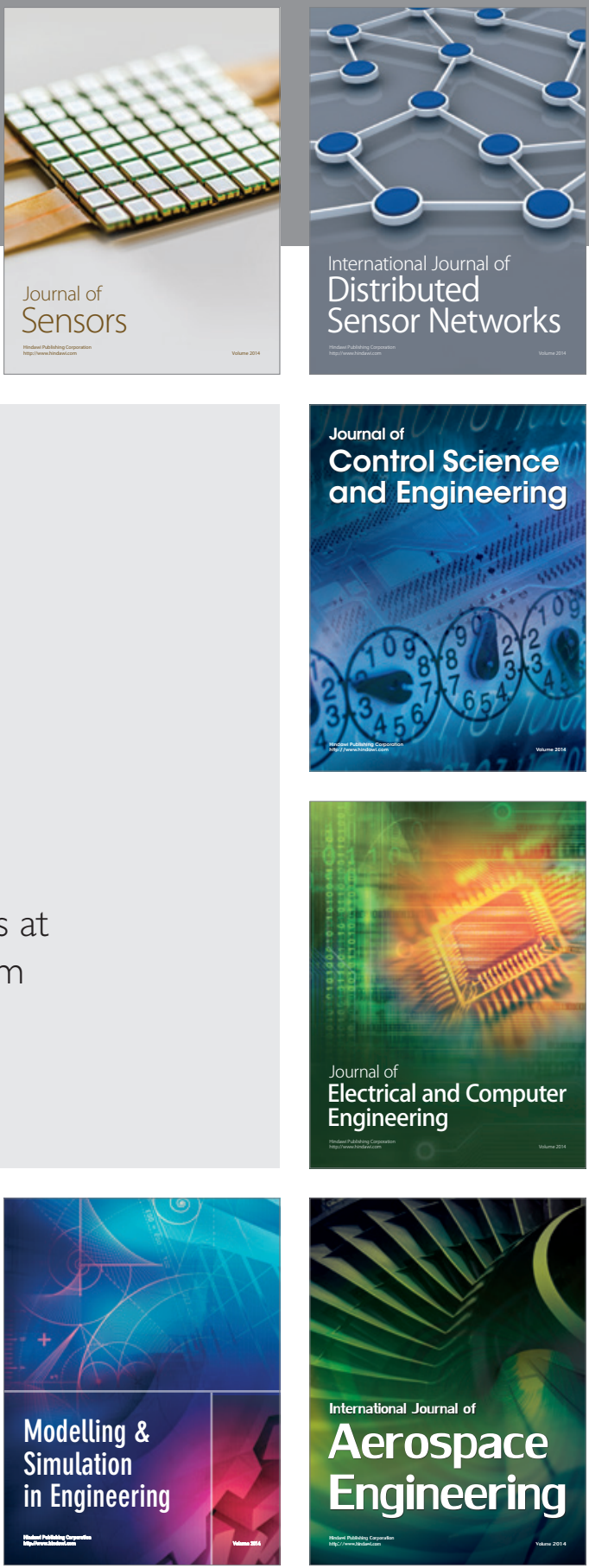

Journal of

Control Science

and Engineering
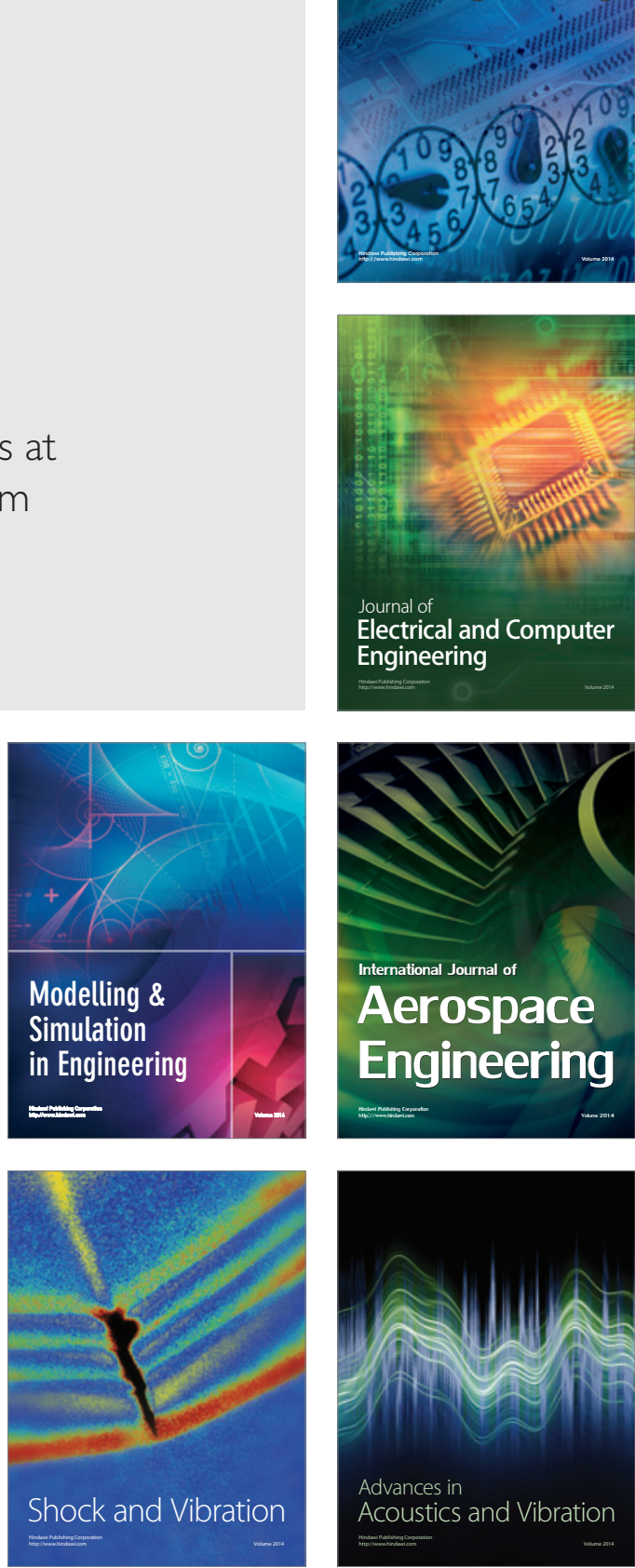